\title{
ORGANOSULFUR COMPOUNDS OF COKE OVEN GAS AND THEIR CONTRIBUTION TO EMISSIONS OF SULFUR DIOXIDE FROM THE SMOKESTACKS OF COKE BATTERIES
}

(C) A.Yu. Martynova, PhD in technical sciences, O.S. Malysh, PhD in technical sciences, V.A. Saraeva, I.N. Palval, PhD in chemical sciences (State Enterprise "Ukrainian State Research Institute for Carbochemistry (UKHIN)", 7, Vesnina Str., 61023, Kharkiv, Ukraine)

The article touches upon the problem of cleaning of the coke oven gas from sulfur compounds, which is relevant in connection with the requirements for reducing of the sulfur dioxide emissions into the atmosphere and ensuring of the environmental safety of production in general. At present, the sulfur dioxide emissions from coke-chemical plants account for about $20 \%$ of the total emissions of pollutants from coke ovens and are calculated from the concentration of hydrogen sulfide in coke oven gas after its purification before feeding to coke oven batteries heating systems. However, in addition to hydrogen sulfide, coke oven gas also contains organosulfur compounds such as carbon disulfide $\left(\mathrm{CS}_{2}\right)$, carbon oxysulfide (COS), thiophene $\left(\mathrm{C}_{4} \mathrm{H}_{4} \mathrm{~S}\right)$, mercaptans, etc.

The authors of the article carried out a study to determine the content of organic sulfur compounds in the original and purified coke oven gas, as well as the contribution of these substances to sulfur dioxide emissions from the smokestacs of coke oven batteries. The calculation has been performed of the additional volume of sulfur dioxide, which is formed due to the combustion of organosulfur compounds of coke oven gas during its combustion in the heating system of coke ovens.

It has been found that under the condition of complete conversion of organic sulfur compounds into sulfur dioxide during the combustion of coke oven gas in the heating system of coke ovens, the concentration of sulfur dioxide in flue gases can be approximately $25.0-35.0 \mathrm{mg} / \mathrm{m}^{3}$ (in recount on $5 \%$ oxygen content in flue gases). It has been also shown that the share of emissions of the sulfur dioxide formed as a result of the combustion of hydrogen sulfide in coke oven gas is 90-95\%, and that formed as a result of combustion of the organic sulfur compounds is 5-10\%, even if they are completely transformed into the sulfur dioxide. It has been concluded that it is legitimate to calculate the volume of sulfur dioxide emissions based on the concentration of hydrogen sulfide in purified coke oven gas, supplied as an energy carrier to the heating system of coke ovens.

Keywords: coke oven gas, organosulfur compounds, emissions of pollutants, sulfur dioxide, environmental safety, technological standards.

Author for correspondence A.Yu. Martynova,e-mail: alla_martynova_aisim@ukr.net 